\title{
MITIGAÇÃO E RESPOSTA DE ENFRENTAMENTO AOS PERÍODOS DE ESTIAGEM DOS AGRICULTORES DE CHAPECÓ (SC)
}

\section{MITIGATION AND COPING RESPONSE TO THE DROUGHT PERIODS OF FARMERS IN CHAPECÓ (SC)}

\author{
Kátia SPINELLI ${ }^{1}$ \\ Rosemy da Silva NASCIMENTO ${ }^{2}$
}

\begin{abstract}
Resumo: Chapecó é um dos municípios de Santa Catarina mais afetados por danos socioeconômicos decorrentes de períodos de estiagem. Os danos afetam sobretudo as atividades da agropecuária. Nesse contexto, esta pesquisa objetivou identificar e analisar as medidas mitigatórias e as respostas de enfrentamento utilizadas pelos agricultores antes, durante e após um período de estiagem em Chapecó (SC). Para tal, utilizou-se a metodologia qualitativa com entrevistas semiestruturadas aplicadas em instituições e agricultores, totalizando 21 pessoas entrevistadas. As instituições entrevistadas foram a Empresa de Pesquisa Agropecuária e Extensão Rural de Santa Catarina (EPAGRI), a Defesa Civil regional e a Secretária do Desenvolvimento Rural e Meio Ambiente da Prefeitura Municipal de Chapecó. Diante das entrevistas realizadas, verificou-se que os agricultores utilizam medidas mitigatórias e de enfrentamento à estiagem de maneira desigual. Alguns agricultores utilizam medidas de enfrentamento suficientes, de acordo com a sua produção agropecuária, para absorver os impactos da estiagem, tornando-os menos vulneráveis a esse perigo; no entanto, outros são incapazes de absorver os danos e são mais vulneráveis aos períodos de estiagem. Tal diferença é demarcada por fatores que interferem na aquisição e no uso das medidas mitigatórias entre os agricultores, como o poder aquisitivo econômico e o acesso a recurso hídrico.
\end{abstract}

Palavras-chave: Estiagem; Mitigação; Agricultura.

\begin{abstract}
Chapecó is one of the most affected cities in Santa Catarina by social and economic damage due to draught periods. The damages affect the farming and cattle raising activities. In this context, this research aims to identify and analyze the lenitive measures and the response adopted by the farmers before, during and after a draught period in Chapecó, Santa Catarina. For that, it has been used the qualitative methodology of semi-structured interviews with institutions and farmers. The institutions interviewed were Empresa de Pesquisa Agropecuária e Extensão Rural de Santa Catarina (EPAGRI), the regional Civil Defense and the Secretary of Rural and Environmental Development of the city hall of Chapecó. After the interviews, it has been noticed that the farmers use lenitive and draught facing measures in an uneven manner. Some farmers use enough draught facing measures, according to their production to absorb the impacts of the draught, thus making them less vulnerable to this peril. On the other hand, others are unable to absorb the damage, becoming more vulnerable during the periods of draught. This different is indicated by factors that interfere in the acquisition and use of lenitive measures among the farmers, such as purchasing power and the access to water resources.
\end{abstract}

Keywords: Draught; Mitigation; Agriculture.

\footnotetext{
1 Professora Doutora do Centro Universitário Leonardo da Vinci (UNIASSELVI). E-mail: katia.spinelli@uniasselvi.com.br.

Professora Doutora da Universidade Federal de Santa Catarina (UFSC). E-mail:
rosemy.nascimento@gmail.com.
} 


\section{Introdução}

O município de Chapecó localiza-se no Oeste de Santa Catarina e se destaca por ser um polo regional em razão da prestação de serviços, do comércio e do setor agroindustrial. Exerce influência sobre a mesorregião Oeste Catarinense e, também, sobre o norte do Rio Grande do Sul e o sudoeste do Paraná (FUJITA, 2013).

Chapecó, assim como o Oeste Catarinense, caracteriza-se pela presença da atividade agroindustrial focada na produção de alimentos e suas cadeias correlatas. Independentemente de haver um crescimento na diversificação de atividades nesse município, 37\% das empresas exportadoras possui relação com o setor agropecuário, tais como indústrias de máquinas e equipamento para frigoríferos, suinocultura, avicultura, bovinocultura ou laboratórios de medicamentos para esse setor. Além disso, em Chapecó, são realizadas feiras de negócios voltadas à agropecuária. Para Fujita (2013), o município de Chapecó se revela nessa interação dialética entre o urbano e o rural.

Percebe-se, assim, a importância econômica do setor agropecuário em Chapecó; este, porém, é exposto a danos e perdas ocasionados por períodos de estiagem. De maneira geral, a estiagem afeta de forma direta perdas na produtividade agropecuária, sendo a produção de grãos a mais atingida. E, de maneira indireta, ocasiona impactos na cadeia produtiva do setor agropecuário, afetando: as feiras e comércio dos produtos coloniais, feira do gado e indústria de beneficiamento. Devido a redução pluviométrica, o processo ainda causa impacto na produção de energia nas usinas hidroelétricas, e também, no abastecimento de água nas áreas urbanas e problemas na saúde humana devido ao consumo alternativo de água muitas vezes imprópria (SPINELLI, 2018).

De acordo com Herrmann (2014), Chapecó é um dos municípios catarinenses que possuiu uma frequência muito alta ${ }^{3}$ de ocorrência de desastre por estiagem. Os registros dos decretos de Emergência e Calamidade Pública entre 1999 e $2017^{4}$ indicam que o município apresentou 12 decretos municipais de Estado de Emergência decorrentes de períodos de estiagem. Eles ocorreram nos anos de 2000, 2002, 2004, 2005, 2006, 2008, 2009, 2011 e 2014.

\footnotetext{
${ }^{3}$ Os municípios catarinenses que tiveram o registro entre 12 e 22 decretos municipais de Estado de Emergência e/ou Calamidade Pública devido à estiagem, no período de 1980 a 2014, foram classificados por Herrmann (2014) em: frequência muito alta de estiagem. Municípios com menos registros foram classificados em frequência alta, média ou baixa/nula.

${ }^{4}$ Disponíveis no site da Defesa Civil de Santa Catarina (2018). 
Climaticamente, os períodos de estiagem que trazem danos ao Oeste Catarinense ocorrem entre os meses de novembro e abril em anos esporádicos. Estes se caracterizam por meses com chuva abaixo da normalidade e poucos dias com chuva, muitas vezes aliados a uma evapotranspiração potencial superior ao volume de chuva mensal (SPINELLI, 2018).

Doubrawa (2007) descreve que as estiagens no Oeste Catarinense podem estar relacionadas ao uso intensivo do solo pelas atividades agropecuárias sem o uso de técnicas de conservação do solo e da água e que os adensamentos das malhas viária, urbana e agroindustrial favoreceram o escoamento superficial da água no solo e o desabastecimento das nascentes. Isso faz com que a demanda por recursos hídricos aumente e favoreça a instalação da crise por falta de água.

Nesse mesmo viés, a pesquisa de Spíndola e Nodari (2012) abordou que os registros de estiagem no Oeste Catarinense têm crescido em decorrência da ação antrópica, como o aumento da população, a introdução de técnicas e a utilização do solo, voltados para a produção capitalista. Dentre as mudanças da paisagem que contribuem para o agravamento da estiagem, destacam-se: aglomerações de edificações, impermeabilização do solo, compactação do solo, desmatamentos e queimadas nas áreas rurais.

Diante das pesquisas analisadas, verifica-se que a estiagem no Oeste Catarinense é resultado de fatores naturais em união a ação antrópica nesse espaço geográfico, originando em alguns anos danos socioeconômicos decorrentes desse perigo.

Autores como Cutter et al. (2008), Romero et al. (2013), Wilhite et al. (2005), entre outros, destacam a relevância da adaptação — também denominada resiliência — da sociedade ou de grupos sociais para reduzir e até sanar os impactos de um perigo.

Romero et al. (2013) salientam que quando a variabilidade do clima se torna um perigo à sociedade, essa deve ser enfrentada mediante complexos processos de aprendizagem, adaptação e mitigação. Wilhite et al. (2005) também destacam que os impactos da seca podem ser reduzidos através de mitigação e preparação que podem ser executadas a partir de um plano de preparação. Para que esse plano seja efetivo, antes é necessário avaliar a exposição e a vulnerabilidade de uma região e/ou de grupos sociais ao perigo.

Mattedi (2010), também, destaca que algumas regiões e/ou grupos sociais se apresentam mais vulneráveis às secas, principalmente aqueles que possuem menor poder aquisitivo e onde não ocorre um planejamento preventivo. 
Diante desses autores, ressalta-se a pertinência de como a sociedade ou grupos sociais lidam e se adaptam a um evento perigoso, tornando-se, assim, mais ou menos vulneráveis a um desastre.

Cutter et al. (2008) fazem uso de um modelo teórico denominado modelo de Disastrer Resilience of Place (DROP) para descrever os fatores que interferem na ocorrência de um desastre. Os autores demonstram que um desastre ocorre por meio de um efeito cumulativo das condições antecedentes, das características do evento e da resposta do enfrentamento.

Os efeitos de um evento perigoso são atenuados ou amplificados pela presença ou ausência de ações de mitigação e resposta de enfrentamento da comunidade, sendo que a resposta de enfrentamento corresponde a ações que permitem que uma comunidade responda imediatamente aos impactos desse evento. Quando uma comunidade efetua respostas de enfrentamento suficientes ao perigo, o impacto do evento será atenuado. Já as ações de mitigação são aquelas que reduzem ou evitam o risco de danos causados por eventos perigosos (CUTTER et al., 2008).

Nesse contexto, e considerando que os períodos de estiagem são capazes de provocar danos econômicos para o setor da agropecuária em Chapecó, este artigo objetiva identificar e analisar as medidas mitigatórias e as respostas de enfrentamento utilizadas pelos agricultores antes, durante e após um período de estiagem em Chapecó (SC).

Entende-se que esta pesquisa possa contribuir para o processo de aprendizagem, de adaptação e de mitigação da estiagem, assim como fornecer subsídio teórico para gestão de políticas públicas mais eficientes na redução da vulnerabilidade e no aumento da resiliência social antes, durante e após um período de estiagem.

\section{Metodologia}

A pesquisa se concentra em escala de análise local, tendo o município de Chapecó como área de pesquisa. Optou-se por esse município porque é um dos mais atingidos por desastres decorrentes de estiagem em Santa Catarina, além de abrigar sedes regionais da Empresa de Pesquisa Agropecuária e Extensão Rural de Santa Catarina (Epagri) e da Defesa Civil, instituições relevantes a serem entrevistadas.

Utilizou-se metodologia qualitativa com entrevistas semiestruturadas a instituições e aos agricultores, totalizando vinte e um entrevistados. Buscou-se realizar as entrevistas de 
forma adequada e com o rigor necessário na fase preparatória, na aplicação e, posteriormente, na análise dos dados.

$\mathrm{Na}$ pesquisa qualitativa se produzem dados com informações ricas em pormenores descritivos, referentes as pessoas, lugares, acontecimentos, registros de depoimentos, entre outros. Tais informações não são próprias para um tratamento estatístico, prevalecendo, assim a destreza interpretativa do pesquisador (NETO, 2013).

Dessa forma, levou-se em consideração que a finalidade da pesquisa qualitativa não é somente a de contar pessoas ou opiniões, mas de explorar as diferentes representações, discursos, ações e as práticas espaciais cotidianas, as histórias de vida e a visão de mundo das pessoas sobre o assunto pesquisado (GASKELL, 2002; NETO, 2013).

A seleção da amostra dos entrevistados considerou a técnica denominada, em inglês, de snowball ou snowball sampling (BIERNACKI; WALDORF, 1981). No Brasil, essa técnica de seleção é designada de "amostragem em bola de neve", ou ainda, como "cadeia de informantes" (RIBEIRO,2020).

Com a utilização dessa técnica de amostra, os participantes iniciais da pesquisa, indicam novos participantes e assim, sucessivamente, até que se encontre um "ponto de saturação". Tal ponto é atingido quando os novos entrevistados repetem os conteúdos já abordados nas entrevistas anteriores (RIBEIRO, 2020).

Neste sentido, o número de entrevistados não carece ser determinado a priori, já que depende da qualidade de informações obtidas em cada depoimento, assim como do grau de recorrência ou de divergência das respostas dos entrevistados (DUARTE, 2002; GASKELL, 2002). Assim, nesta pesquisa considerou-se a finalização das entrevistas quando se identificou o ponto de saturação nas respostas dos entrevistados e a compreensão necessária para alcançar os objetivos da pesquisa.

A título de exemplificação, Murara (2016), por meio de pesquisa qualitativa e com o uso de entrevistas, considerando a "amostragem em bola de neve", identificou medidas adaptativas utilizadas pela população mais vulnerável a inundações em Rio do Sul (SC). Essa finalidade vai ao encontro do que se busca nesta pesquisa, que é verificar as diversas ações realizadas pelos agricultores para enfrentar os períodos de estiagem que culminaram em perdas socioeconômicas.

Diante disso, na fase preparatória desta pesquisa, elaboraram-se perguntas semiestruturadas alinhadas ao objetivo da pesquisa. Elas buscaram identificar as medidas 
mitigatórias utilizadas pelos agricultores, focando três eixos principais: a) antes do desastre; b) durante o desastre; e c) pós-desastre.

Com base nessas considerações, buscou-se entrevistar instituições que estão envolvidas com o tema de pesquisa e agricultores. As instituições entrevistadas foram: Epagri, Defesa Civil e Secretária do Desenvolvimento Rural e Meio Ambiente da Prefeitura Municipal.

Para fazer o primeiro contato com as instituições e durante a realização das entrevistas, utilizou-se o sistema de rede. Nesse sistema, busca-se um "informante" que possui informações a respeito do segmento social em estudo e, dessa forma, é possível indicar pessoas ou mapear o campo de investigação (DUARTE, 2002; RIBEIRO, 2000).

Esse procedimento ocorreu dentro das instituições, de modo que um "informante" levava a outro, ampliando o universo dos entrevistados e alcançando pessoas qualificadas para responder às perguntas feitas, atingindo, assim, os objetos propostos na pesquisa. Ao mesmo tempo, dois funcionários da Secretaria do Desenvolvimento Rural e Meio Ambiente atuaram como "informantes" para chegar até os agricultores, já que ambos trabalham diretamente com esse público.

As saídas de campo para Chapecó ocorreram em duas etapas. A primeira delas, com o objetivo de entrevistar as instituições; em um segundo momento, os agricultores foram entrevistados.

Diante das considerações, entrevistaram-se cinco funcionários do Centro de Treinamento e de Pesquisa da Epagri e seis funcionários públicos da Secretária de Desenvolvimento Rural e Meio Ambiente da prefeitura de Chapecó.

No dia da entrevista com a Defesa Civil, ocorreu um imprevisto com o entrevistado e representante dessa instituição. Como nenhum outro funcionário teria propriedade para responder adequadamente às perguntas, optou-se por utilizar as perguntas em forma de questionário. Assim, o questionário foi respondido posteriormente pelo representante da Defesa Civil Regional.

Foram entrevistados nove agricultores: dois deles estavam presentes na Secretária de Desenvolvimento Rural e do Meio Ambiente no dia em que foi realizada a entrevista com os funcionários públicos; os demais foram entrevistados em suas moradias rurais. Dessa forma, totalizaram-se 21 pessoas entrevistadas, sendo que uma delas foi com a aplicação de questionário. A tabela 1 demonstra essa quantificação. 
Tabela 1 - Número de pessoas entrevistadas em Chapecó.

\begin{tabular}{c|c}
\hline Instituição ou agricultor & $\begin{array}{c}\text { Número de pessoas } \\
\text { entrevistadas }\end{array}$ \\
\hline Epagri & 5 \\
\hline Defesa Civil & 1 \\
\hline $\begin{array}{c}\text { Secretária Municipal da } \\
\text { Agricultura }\end{array}$ & 6 \\
\hline Agricultores & 9 \\
\hline
\end{tabular}

Fonte: próprio autor.

Quadro 1 - Principais atividades econômicas produzidas pelos agricultores que foram entrevistados.

\begin{tabular}{|l|l|l|}
\hline \multicolumn{1}{|c|}{$\begin{array}{c}\text { Agricultores } \\
\text { entrevistados }\end{array}$} & $\begin{array}{c}\text { Principais atividades } \\
\text { econômicas da propriedade } \\
\text { rural }\end{array}$ & \multicolumn{1}{|c|}{ Sexo } \\
\hline Agricultor 1 & Aves, leite e milho. & Masculino \\
\hline Agricultor 2 & Milho e leite. & Masculino \\
\hline Agricultor 3 & Aves, milho e/ou soja. & Masculino \\
\hline Agricultor 4 & Leite e suínos. & Feminino \\
\hline Agricultor 5 & Suínos. & Feminino \\
\hline Agricultor 6 & Milho e soja. & Masculino \\
\hline Agricultor 7 & Aves, suínos e leite. & Feminino \\
\hline Agricultor 8 & Laranja e Eucalipto. & Masculino \\
\hline Agricultor 9 & Hortaliça & Masculino \\
\hline
\end{tabular}

Fonte: próprio autor.

Buscou-se entrevistar agricultores que tivessem características diferentes em relação à produção agropecuária e às suas localidades. O quadro 1 demonstra as principais atividades econômicas de cada agricultor entrevistado. As diferentes características foram importantes para relacionar as medidas mitigatórias utilizadas pelos agricultores em distintas realidades.

Para análise das entrevistas, foi utilizado o método de Análise de Conteúdo (AC), o qual compreende um conjunto de técnicas de pesquisa que busca a análise de sentido ou sentidos acerca de um conteúdo.

A análise de conteúdo, nesta pesquisa, fundamenta-se na análise descrita por Laurence Bardin (1977). Tal método é comumente utilizado nas pesquisas acadêmicas, principalmente nas áreas de ciências humanas (CAMPOS, 2004; CAMARA, 2013).

Ante os pressupostos da metodologia de AC, foram analisadas as respostas das entrevistas dos agricultores classificando em categorias, subcategorias e temas que estão discriminados no quadro 2. 
Quadro 2 - Classificação das respostas dos entrevistados em Categorias, Subcategorias e Temas.

\begin{tabular}{|c|c|c|}
\hline Categorias & Subcategorias & Temas \\
\hline $\begin{array}{c}\text { Agricultores sofrem danos } \\
\text { com a estiagem. }\end{array}$ & \multirow{2}{*}{$\begin{array}{c}\text { Agricultores - } \\
\text { denominações (A } \\
\text { ao I) }\end{array}$} & \multirow{2}{*}{$\begin{array}{l}\text { - Resposta de enfrentamento. } \\
\text { - Mitigação. } \\
\text { - Outras considerações. }\end{array}$} \\
\hline $\begin{array}{l}\text { Agricultores não sofrem } \\
\text { danos com a estiagem. }\end{array}$ & & \\
\hline Instituições entrevistadas & $\begin{array}{l}\text { Nome da } \\
\text { instituição }\end{array}$ & $\begin{array}{c}\text { - Ações institucionais } \\
\text { mitigatórias. } \\
\text { - Medidas mitigatórias utilizadas } \\
\text { pelos agricultores. }\end{array}$ \\
\hline
\end{tabular}

Fonte: próprio autor.

\section{Mitigação e resposta de enfrentamento dos agricultores à estiagem: análise das entrevistas}

A pesquisa realizada não abordou, somente, as experiencias vivenciadas pelos agricultores em um único episódio de estiagem, mas é resultado de um conjunto de experiências somadas em diversos períodos de estiagem que ocorreram em Chapecó. O que permite identificar e analisar se as medidas de mitigação e respostas de enfrentamento que estão sendo utilizadas pelos agricultores são suficientes para amenizar os danos provocados pela estiagem.

De acordo com as respostas dos agricultores entrevistados, observou-se que alguns deles disseram-se afetados economicamente pelos períodos de estiagem, visto que a falta de chuva trazia danos as suas produções agropecuárias. Outros agricultores falaram que, apesar da ocorrência de estiagem, esta não trazia grandes danos à produção agropecuária, o que não chegava a causar um impacto financeiro decorrente da estiagem.

Dessa forma, separou-se a análise das entrevistas com os agricultores em duas categorias: agricultores que sofrem danos e agricultores que não sofrem danos com os períodos de estiagem, considerando as suas respostas. O quadro 3 demonstra os itens analisados nessas duas categorias. 
Quadro 3 - Análise da resposta dos agricultores entrevistados.

\begin{tabular}{|c|c|c|c|c|}
\hline Categoria & Agricultor & $\begin{array}{l}\text { Principais } \\
\text { produtos } \\
\text { agrícolas }\end{array}$ & $\begin{array}{c}\text { Resposta de } \\
\text { enfrentamento }\end{array}$ & Mitigação \\
\hline \multirow{5}{*}{ 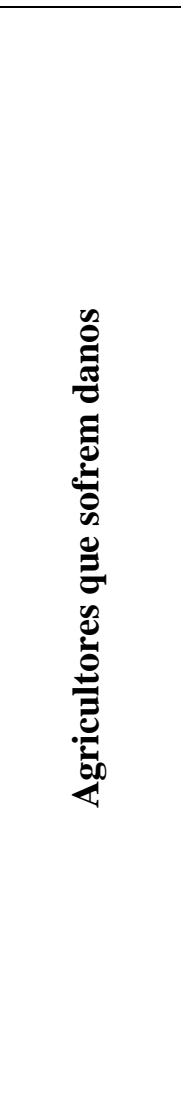 } & $\begin{array}{c}\text { Agricultor } \\
\text { A }\end{array}$ & $\begin{array}{l}\text { Aviário e } \\
\text { produção } \\
\text { de grãos. }\end{array}$ & $\begin{array}{l}\text { - Solicita caminhão- } \\
\text { pipa à prefeitura. } \\
\text { - Busca água do Rio } \\
\text { Uruguai. }\end{array}$ & $\begin{array}{l}\text { - Perfuração de } \\
\text { poços d'água. } \\
\text { - Plantio de soja } \\
\text { precoce. }\end{array}$ \\
\hline & $\begin{array}{c}\text { Agricultor } \\
\text { B }\end{array}$ & $\begin{array}{l}\text { Leite, suíno } \\
\text { e milho. }\end{array}$ & $\begin{array}{l}\text { - Solicita caminhão- } \\
\text { pipa à prefeitura. } \\
\text { - Venda de suínos. } \\
\text { - Racionamento de } \\
\text { água para consumo } \\
\text { humano. }\end{array}$ & $\begin{array}{c}\text { - Poço comunitário. } \\
\text { - Renda da esposa e } \\
\text { do filho (trabalho } \\
\text { urbano). }\end{array}$ \\
\hline & $\begin{array}{c}\text { Agricultora } \\
\text { D }\end{array}$ & $\begin{array}{l}\text { Milho, soja } \\
\text { e aves. }\end{array}$ & - Venda de aves. & $\begin{array}{l}\text { - Abertura de poço } \\
\text { em conjunto com } \\
\text { outra família de } \\
\text { agricultores. }\end{array}$ \\
\hline & $\begin{array}{l}\text { Agricultora } \\
\text { E }\end{array}$ & $\begin{array}{l}\text { Suínos, } \\
\text { aves, leite e } \\
\text { milho. }\end{array}$ & $\begin{array}{l}\text { - Racionamento de } \\
\text { água para o } \\
\text { consumo humano. } \\
\text { - Solicita caminhão- } \\
\text { pipa à prefeitura. }\end{array}$ & $\begin{array}{l}\text { - Perfuração de } \\
\text { poços d'água. } \\
\text { - Estoque de } \\
\text { silagem. }\end{array}$ \\
\hline & $\begin{array}{c}\text { Agricultor } \\
\mathrm{H}\end{array}$ & $\begin{array}{l}\text { Milho, leite } \\
\text { e aves. }\end{array}$ & $\begin{array}{l}\text { - Protela o } \\
\text { pagamento do } \\
\text { empréstimo. } \\
\text { - Venda de aves. }\end{array}$ & $\begin{array}{l}\text { - Construção de } \\
\text { cisterna. }\end{array}$ \\
\hline \multirow{4}{*}{ 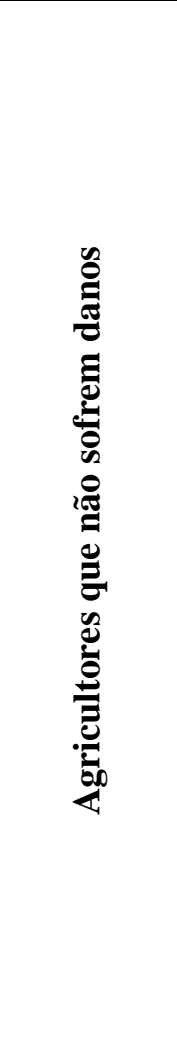 } & $\begin{array}{l}\text { Agricultor } \\
\text { C }\end{array}$ & $\begin{array}{l}\text { Somente a } \\
\text { suinocultur } \\
\text { a. }\end{array}$ & $\begin{array}{l}\text { - Um poço d'água é } \\
\text { destinado somente } \\
\text { para a } \\
\text { dessedentação dos } \\
\text { animais. }\end{array}$ & $\begin{array}{c}\text { - Perfurou dois } \\
\text { poços d'água } \\
\text { (consumo próprio e } \\
\text { dessedentação). } \\
\text { - Compra silagem } \\
\text { para alimentação dos } \\
\text { suínos. }\end{array}$ \\
\hline & $\begin{array}{l}\text { Agricultor } \\
\text { F }\end{array}$ & Laranja. & $\begin{array}{l}\text { - Utiliza água da } \\
\text { cisterna nos } \\
\text { processos da } \\
\text { produção. }\end{array}$ & $\begin{array}{c}\text { - Mudança na } \\
\text { produção agrícola, } \\
\text { trocou o milho e o } \\
\text { aviário pela } \\
\text { produção de laranja. } \\
\text { - Possui duas } \\
\text { cisternas. }\end{array}$ \\
\hline & $\begin{array}{l}\text { Agricultora } \\
\text { G }\end{array}$ & $\begin{array}{l}\text { Hortaliças } \\
\text { orgânicas. }\end{array}$ & - Utiliza a irrigação. & $\begin{array}{l}\text { - Possui sistema de } \\
\text { irrigação. } \\
\text { - Possui três fontes } \\
\text { de água em sua } \\
\text { residência. }\end{array}$ \\
\hline & Agricultor I & $\begin{array}{l}\text { Milho e } \\
\text { leite. }\end{array}$ & $\begin{array}{l}\text { - Utiliza o estoque } \\
\text { de silagem para } \\
\text { manter a produção } \\
\text { de leite. }\end{array}$ & $\begin{array}{c}\text { - Estoque de } \\
\text { silagem. } \\
\text { - Possui sistema de } \\
\text { irrigação para o } \\
\text { milho. }\end{array}$ \\
\hline
\end{tabular}

Fonte: próprio autor. 
Conforme o quadro 3, os agricultores que sofrem danos com os períodos de estiagem se utilizam das seguintes respostas de enfrentamento: solicitam caminhão-pipa à prefeitura, transportam água do Rio Uruguai à sua propriedade e fazem racionamento doméstico no uso da água para destinar maior quantidade à dessedentação de animais. Do ponto de vista econômico, as respostas utilizadas para enfrentar os prejuízos provocados durante um período de estiagem foram a venda de suínos e aves e o protelamento do pagamento do empréstimo bancário que pode ser efetivado através de laudo técnico de perdas fornecido pela Epagri ao agricultor. Em relação às medidas mitigatórias utilizadas por esse mesmo grupo de agricultores, destacam-se: perfuração de poços d'água particulares de maneira individual ou em conjunto com membros familiares ou vizinhos; abertura de poços comunitários com auxílio da prefeitura; estoque de silagem; construção de cisterna; e plantio de soja precoce, conforme previsão do tempo.

Já os agricultores que responderam que a estiagem não provoca prejuízos em suas produções agrícolas se utilizam das seguintes medidas mitigatórias: irrigação, construção de cisternas, estoque ou compra de silagem, abertura de poços particulares e substituição de plantação de milho por outra produção mais resistente a um período com estiagem.

Diante desse contexto, verifica-se que tanto os agricultores que são afetados como aqueles que não são afetados por danos decorrentes da estiagem utilizam alguma medida mitigatória e de enfrentamento, sendo que algumas delas se repetiram entre os dois grupos: abertura de poços d'água, construção de cisterna e estoque de silagem. Contudo, aqueles agricultores que não sofrem danos econômicos decorrentes da estiagem (agricultores $\mathrm{C}, \mathrm{F}, \mathrm{G}$ e I) fazem uso de medidas mitigatórias mais eficientes, conforme suas produções agrícolas.

$\mathrm{O}$ agricultor $\mathrm{C}$, que tinha a suinocultura como principal fonte de renda, mantinha sua produção sem perdas durante a estiagem porque fazia uso da água do poço de sua residência para manter a produção. Nesse mesmo viés, a agricultora $G$ possuía uma pequena produção orgânica e se utilizava de um sistema de irrigação, não sendo afetada pelos períodos de escassez de precipitação. E o agricultor I mantinha estoque de silagem, o que garantia produtividade do leite em períodos de estiagem, e a produção de milho era mantida pelo processo de irrigação que possuía em sua propriedade.

Já o agricultor $\mathrm{F}$, que tem a produção de laranja como principal fonte de renda, relatou durante a entrevista que a laranja não é fortemente afetada pelos períodos de estiagem que atingem a região, de modo que, quando a estiagem cessa, a produtividade da laranja se recupera - o que garante rentabilidade em sua produção mesmo durante um período de 
estiagem. Além disso, o agricultor $\mathrm{F}$ possui duas cisternas em sua residência, fator que garante, em períodos de escassez de água, a manutenção de alguns processos de sua produção, como a lavagem do fruto.

Além das entrevistas com os agricultores, as perguntas feitas às instituições também ofereceram dados sobre as medidas mitigatórias utilizadas pelos agricultores no município de Chapecó. O quadro 4 demonstra a resposta dos representantes entrevistados da Defesa Civil, Epagri e Secretária do Meio Ambiente e Desenvolvimento Rural de Chapecó sobre as medidas mitigatórias utilizadas pelos agricultores no município.

Quadro 4 - Análise das entrevistas com representantes das instituições.

\begin{tabular}{|c|c|}
\hline Nome da instituição & Medidas mitigatórias utilizadas pelos agricultores \\
\hline $\begin{array}{l}\text { Empresa de Pesquisa } \\
\text { Agropecuária e Extensão } \\
\text { Rural de Santa Catarina - } \\
\text { Epagri }\end{array}$ & $\begin{array}{l}\text { - Adiam o pagamento do empréstimo bancário. } \\
\text { - Constroem cisternas. } \\
\text { - Abrem poços profundos. }\end{array}$ \\
\hline $\begin{array}{l}\text { Secretaria do Meio Ambiente } \\
\text { e Desenvolvimento Rural de } \\
\text { Chapecó }\end{array}$ & $\begin{array}{l}\text { - Abrem poços. } \\
\text { - Armazenam silagem. } \\
\text { - Adiam o pagamento do empréstimo bancário. }\end{array}$ \\
\hline $\begin{array}{l}\text { Defesa Civil do município de } \\
\text { Chapecó. }\end{array}$ & $\begin{array}{l}\text { - Aquisição de cisternas. } \\
\text { - Abertura de poços. }\end{array}$ \\
\hline
\end{tabular}

Fonte: próprio autor.

No quadro 4, é possível verificar que as respostas dadas pelas instituições entrevistadas coincidem com as respostas dos agricultores. Desse modo, as medidas que foram salientadas são: abertura de poços, construção de cisternas, armazenamento de silagem e adiamento do pagamento do empréstimo bancário, através de laudo técnico de perda de safra.

Um dos entrevistados da Epagri relatou que "de maneira geral, a agricultura e a maneira como o agricultor se adapta à estiagem é igual em todo o entorno de Chapecó". Ainda, mensurou que cerca de $40 \%$ dos agricultores utilizam medidas mitigatórias em relação à estiagem; o restante ainda não tem essa percepção de se preparar para enfrentar os períodos mais secos.

Dois dos entrevistados da Secretaria do Meio Ambiente e Desenvolvimento Rural também mencionaram que são poucos os agricultores que utilizam medidas mitigatórias à estiagem no município de Chapecó. O primeiro deles falou que "o agricultor não tem o hábito de trabalhar com medidas preventivas. O agricultor tem memória curta em relação à estiagem". 
A segunda entrevistada declarou que "grande parte dos agricultores tem uma ação momentânea diante da estiagem, são poucos que se preocupam com uma medida adaptativa em longo prazo". A ação momentânea relatada por ela seria a abertura de poços e a solicitação de caminhão-pipa.

\section{Fatores que interferem no uso das medidas mitigatórias e de enfrentamento da estiagem}

Perante esse levantamento de medidas mitigatórias e de enfrentamento da estiagem utilizadas pelos agricultores, é possível dividir essas medidas, de acordo com Wilches-Chau (1993), em estruturais e não estruturais. As estruturais podem ser consideradas: a abertura de poços, a construção de cisternas, a implantação de sistema de irrigação, o armazenamento de silagem e o transporte de água por caminhão-pipa. As medidas não estruturais são o racionamento de água para consumo humano, a policultura, a substituição da produção de grãos por outra menos afetada pela estiagem e o protelamento da dívida bancária. A figura 1 demonstra um esquema explicativo acerca dessas informações.

Figura 1 - Medidas estruturais e não estruturais utilizadas pelos agricultores de Chapecó para mitigar e/ou enfrentar os períodos de estiagem.

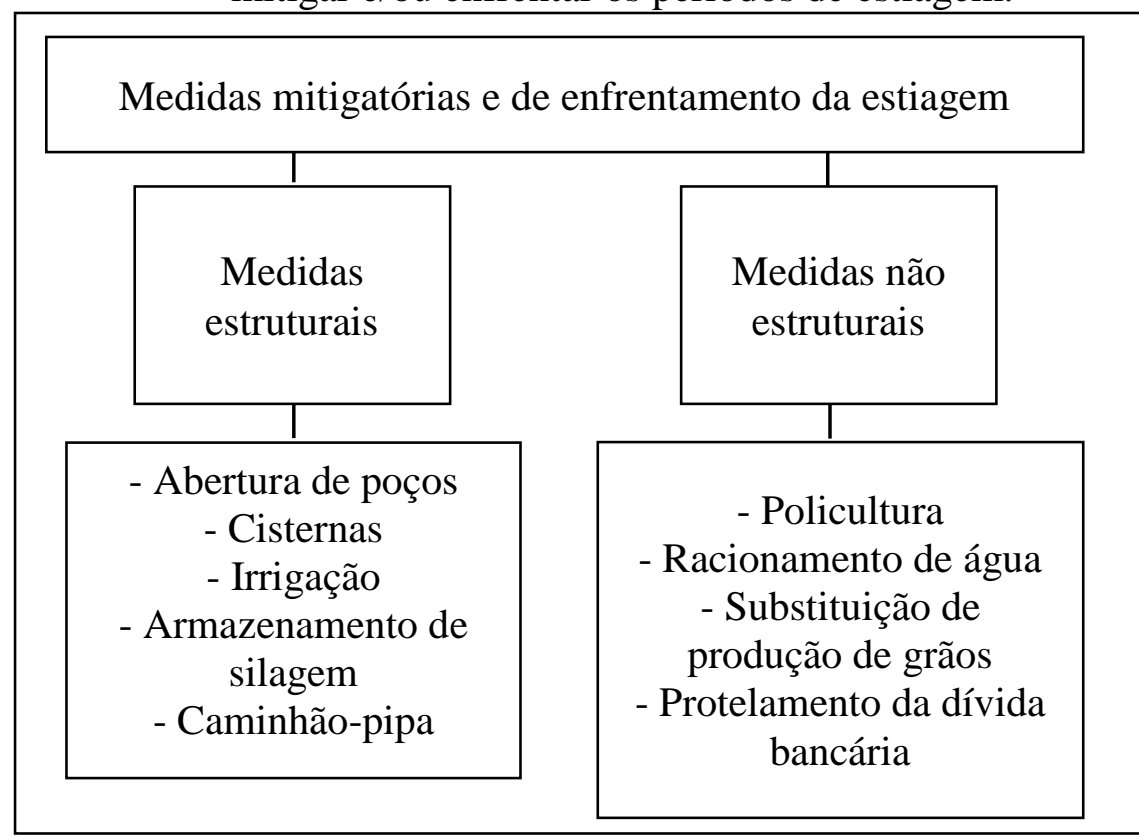

Fonte: próprio autor 
De maneira geral, as medidas não estruturais utilizadas pelos agricultores em Chapecó são capazes de reduzir o impacto da estiagem, mas são menos eficientes que as estruturais. Por exemplo, o racionamento do uso da água doméstica pela família para conseguir destinar água para dessedentação dos animais ou o protelamento da dívida bancária que o agricultor pode solicitar quando ele sofreu danos com a estiagem.

A policultura também foi apontada por alguns agricultores entrevistados como sendo uma forma de reduzir os prejuízos econômicos com os produtos mais afetados pela estiagem. Destacou-se nas falas dos agricultores B, D e H, os quais mencionaram que a venda de aves e/ou suínos era a alternativa econômica para suprir as perdas provocadas pela estiagem na produção de milho. Além disso, a substituição da produção de milho por outra menos afetada pelas estiagens foi uma solução encontrada pelo agricultor $\mathrm{F}$ para reduzir os danos com a estiagem, o qual substituiu a produção de milhos e aves por cultivo de laranja.

Em relação às medidas estruturais - algumas delas como as cisternas, a abertura de poços d'água e o sistema de irrigação - , estas podem garantir um menor impacto das perdas agropecuárias, já que podem suprir a produção agropecuária com a quantidade de água necessária no período de estiagem. No entanto, são medidas que precisam de um maior poder aquisitivo por parte dos agricultores e acesso à água subterrânea, no caso da abertura de poços.

Aquele agricultor que tem acesso a recursos hídricos em sua propriedade rural poderá implementar a abertura de poços d'água ou um sistema de irrigação, podendo enfrentar os períodos de estiagem com menos danos. Alguns agricultores, também, abrem poços em conjunto com familiares ou vizinhos. Assim, conseguem repartir custos e usufruir simultaneamente do recurso hídrico que, por vezes, não está disponível em toda a propriedade rural.

Em Chapecó, ocorre uma diferença espacial quanto à disponibilidade de água subterrânea, conforme estudo e mapeamento realizado pela prefeitura municipal de Chapecó no projeto “Água Boa”. A leste, sudeste e sudoeste do município encontram-se os lugares com menor disponibilidade de água subterrânea, onde se localizam os aquíferos locais e limitados e os aquíferos fraturados de menor potencialidade. O restante do município apresenta aquífero fraturado de maior potencialidade. Assim, faz com que os moradores de Chapecó usufruam de espaços com diferentes potencialidades de exploração da água subterrânea. A figura 2 demonstra esse mapeamento realizado pela prefeitura, por meio dela, 
$\mathrm{EM}$

QUESTÃO

é possível visualizar com mais detalhes a localização dos aquíferos com maior e menor potencialidade.

Figura 2 - Tipos de aquíferos no município de Chapecó (SC).

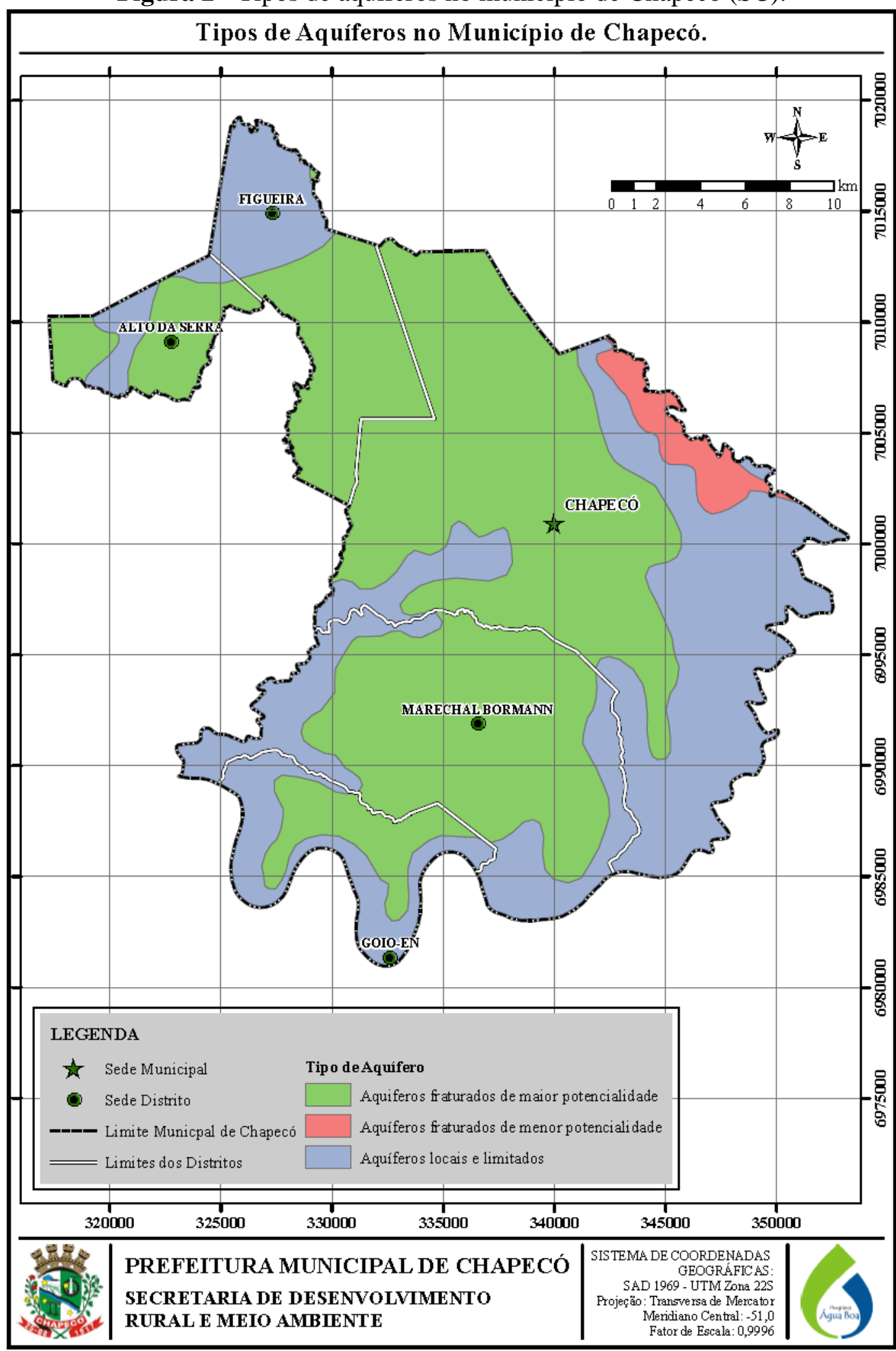

Fonte: Prefeitura Municipal de Chapecó. 
Como a abertura de poços é uma medida utilizada pelos agricultores para suprir necessidades de consumo familiar e da produção durante um período de estiagem, a diferenciação espacial de acesso à água pode impactar exposição a eventuais danos decorrentes da estiagem. Ressalta-se que essa prática não pode estar desvinculada de um planejamento e de fiscalização, a fim de preservar esse recurso hídrico disponível na região. Sem o devido planejamento, pode provocar superexploração e contaminação do recurso subterrâneo, o que agravará os impactos da estiagem futuramente.

Além da abertura de poços, outra medida estrutural utilizada pelos agricultores é o uso de cisternas. Segundo entrevistados da Epagri, seu uso é viável para a dessedentação de animais e irrigação de hortaliças. Nesse último caso, há em Chapecó uma Unidade Demonstrativa de Tecnologia Social (UDTS) implantada em conjunto com o agricultor Lindomar Luzzi e em parceria com o projeto Tecnologia Social para Gestão da Água TSGA ${ }^{5}$.

Nesse estabelecimento rural, houve a construção de um sistema de captação e aproveitamento da água da chuva para a produção de hortaliças orgânicas. A água da chuva é captada das estufas, repassada para o pré-filtro e filtro e armazenada na cisterna. Posteriormente, a água é utilizada na irrigação das hortaliças (BALDISSERA et al, 2015; PROJETO TSGA, 2017). A figura 3 demonstra o sistema de captação da água da chuva na UDST de Chapecó.

Figura 3 - Sistema de captação de água da chuva na UDTS de Chapecó na propriedade rural do agricultor Lindomar Luzzi.

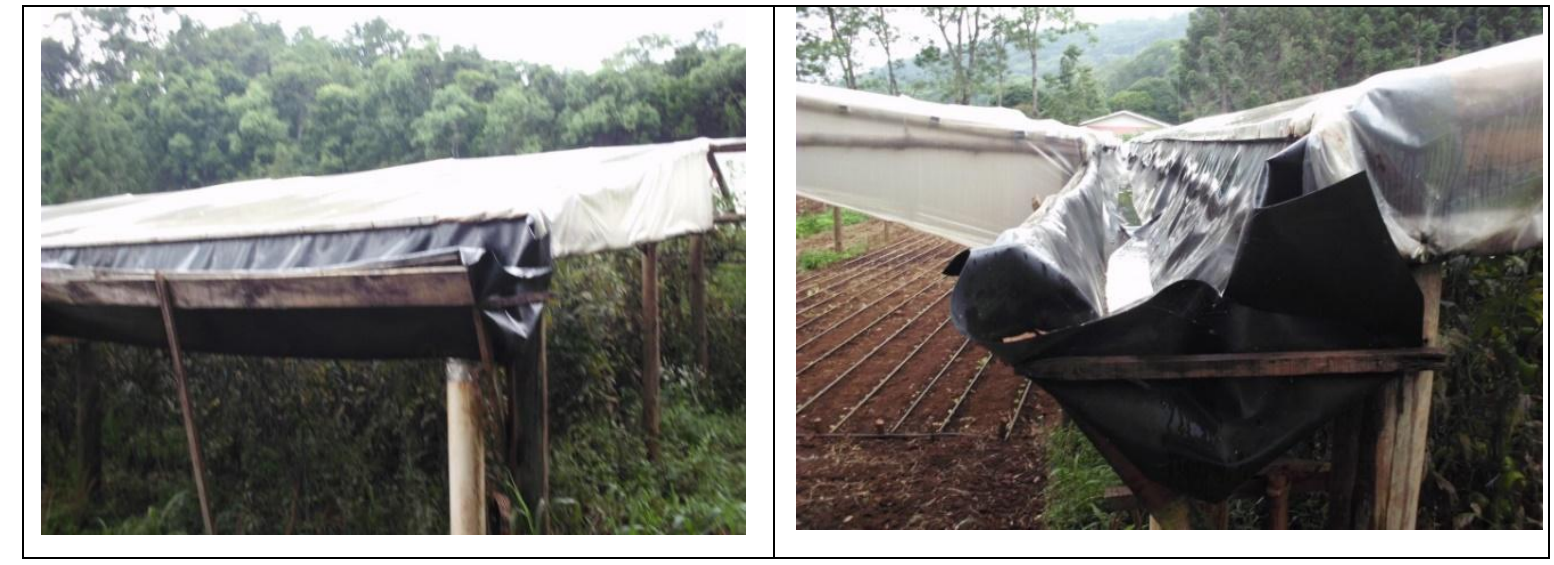

Fotografia: próprio autor.

${ }^{5} \mathrm{O}$ projeto se iniciou em 2007 com o objetivo de "fortalecer o uso sustentável da água através do apoio à capacidade de gestão local de comunidades de bacias hidrográficas em Santa Catarina, integrado à disseminação e implementação de tecnologias sociais na produção de alimentos e saneamento do meio rural" (PROJETO TSGA). Esse projeto conta com o apoio da UFSC, Epagri e Petrobrás. 
A cisterna também pode ser utilizada na produção de suínos, de aves e na bovinocultura de corte e de leite. Para a dessedentação de animais, é necessário que a água da chuva armazenada passe por um sistema de tratamento, objetivando garantir a qualidade sanitária da água (BALDISSERA el al., 2015).

Já para a produção de grãos, a medida mitigatória mais adequada é a irrigação. De acordo com um dos entrevistados da Epagri e outro da Secretaria do Meio Ambiente e Desenvolvimento Rural, a irrigação é uma medida pouco utilizada pelos agricultores em Chapecó, pois se torna viável economicamente somente em pequenas propriedades.

Desse modo, a construção de cisterna e o sistema de irrigação são medidas mitigatórias eficientes para reduzir os impactos em um período de estiagem. Porém, ambas necessitam de investimento financeiro, o que requer, muitas vezes, empréstimos bancários.

Outra medida estrutural utilizada pelos agricultores é o armazenamento de silagem para alimentação de animais, principalmente bovinos. Um dos entrevistados da Secretaria do Meio Ambiente e Desenvolvimento Rural falou que "o armazenamento de silagem é caro, precisa de galpão e mãos de obra, então nem todo o agricultor possui isso", demonstrando, dessa forma, que se trata de mais uma medida mitigatória que não está disponível a todos os agricultores, devido ao custo econômico.

Diante dessa análise, verifica-se que alguns fatores interferem no uso das medidas estruturais que absorvem ou diminuem os impactos dos períodos de estiagem. São eles:

1. O acesso da propriedade rural a recursos hídricos, o que possibilita a abertura de poços d'água;

2. A condição financeira suficiente para investir em medidas mitigatórias mais eficientes, como construção de cisternas e sistema de irrigação.

Esses fatores fazem com que a capacidade de absorção dos agricultores ocorra de forma desigual, atingindo, de forma individualizada, alguns, enquanto outros estão mais vulneráveis aos danos de um período de estiagem. Tal afirmação verifica-se entre os agricultores entrevistados, pois alguns abordaram que são afetados economicamente pelos períodos de estiagem e outros não.

Faz-se necessário uma gestão pública voltada ao desenvolvimento regional dos agricultores, com frente à ascensão econômica e ao planejamento de redução dos impactos agropecuários devido à perigos naturais. A fim de reduzir o risco e os impactos econômicos 
da estiagem, seria pertinente elaborar, institucionalizar e executar um plano de mitigação específico à estiagem, capaz de atingir de maneira mais igualitária os agricultores e outros grupos sociais que sofram danos devido a esse desastre.

Uma comunidade raramente irá elaborar e executar um plano de redução do risco de maneira isolada, mas para isso se efetivar é necessário que estejam conectadas em um contexto mais amplo, envolvendo várias esferas governamentais, sociais e profissionais. Assim, inclui o trabalho de diversos profissionais e cientistas, organizações, agências de ajuda internacional, governo, ONGs, organizações da sociedade civil e representantes da comunidade mais vulnerável ao perigo (TWIGG, 2004).

\section{Considerações finais}

De acordo com as entrevistas realizadas nesta pesquisa, separou-se as medidas mitigatórias e de enfretamento à estiagem pelos agricultores de Chapecó, que se dividiram em estruturais e não estruturais. Assim, as estruturais englobaram a abertura de poços, a construção de cisternas, a implantação de sistema de irrigação, o armazenamento de silagem e o transporte de água por caminhão-pipa. As medidas não estruturais abarcaram o racionamento de água para consumo humano, a policultura, a substituição da produção de grãos por outra menos afetada pela estiagem e o protelamento da dívida bancária.

As entrevistas realizadas em Chapecó demonstraram que os agricultores utilizam essas medidas mitigatórias e de enfrentamento da estiagem de maneira desigual. Alguns agricultores utilizam medidas de enfrentamento suficientes, de acordo com a sua produção agropecuária, para absorver os impactos da estiagem, tornando-os menos vulneráveis a esse perigo (casos esses dos agricultores entrevistados que falaram não ser afetados economicamente pelos períodos de estiagem). No entanto, outros agricultores tem baixa capacidade de suportar os danos e são mais vulneráveis aos períodos de estiagem. Tal diferença é demarcada por fatores que interferem na aquisição e no uso das medidas mitigatórias entre os agricultores, como o poder aquisitivo econômico e o acesso a recurso hídrico.

$\mathrm{O}$ acesso a recursos hídricos faz com que alguns agricultores tenham mais disponibilidade em sua propriedade rural a fontes de água e à água subterrânea, importante para abertura de poços d'água. Já o poder econômico por parte dos agricultores possibilita o 
investimento em medidas mitigatórias estruturais, como construção de cisternas, sistema de irrigação e armazenamento de silagem, sendo que tais medidas são mais eficientes na absorção dos danos provocados pela estiagem.

Nesse contexto, encontra-se um cenário desigual entre os agricultores de Chapecó, onde alguns são mais vulneráveis aos impactos da estiagem. A fim de diminuir os danos provocados pela estiagem de maneira mais igualitária se faz necessário elaborar, institucionalizar e executar um plano de mitigação à estiagem específico à realidade do município. Para tal é imprescindível a participação e colaboração entre várias esferas governamentais, científica, institucionais, além da sociedade civil.

\section{Referências}

BARDIN, L. Análise de conteúdo. Portugal: edições 70, p. 229, 1977.

BALDISSERA, I. T.; STEFFENS, R. F.; OLIVEIRA, Y. V. de; KLOCK, A. L. S. Cisternas: Construção, utilização e manutenção. Florianópolis: Epagri, 2015. 32 p. (Boletim técnico, 167).

BIERMACK, P. WANDORF, D. Snowbool Sampling: problens and techniques of chain referral sampling. Sociological Methods e Research. Vol. 2. November 141. 1981, 141-163 p.

CUTTER, S.L.; BARNES, L.; BERRY, M.; BURTON, E.E.; TATE, E.; WEBB, J. A placebased model for understanding community resilience to natural disasters. Global Environmental Change, 18, 2008, p. 598-606.

DEFESA CIVIL DE SANTA CATARINA. Decretação de SE e ECP. Disponível em: http://www.defesacivil.sc.gov.br/index.php/municipios/decretacoes.html?limitstart=0. Acesso em: 10 jun. 2015.

DOUBRAWA, A. A crise de água e sua possível relação com os parcos remanescentes florestais na região oeste do estado de Santa Catarina. Blumenau: Centro de Ciências Biológicas, Universidade Regional de Blumenau - FURB, 2007. 178 p. (Dissertação de mestrado em Engenharia Ambiental).

DUARTE, R. Pesquisa qualitativa: reflexões sobre o trabalho de campo. Caderno de Pesquisa. n. 115, março/2002, p. 139-154.

FUJITA, C. Chapecó: estrutura e dinâmica de uma cidade média no oeste catarinense. Geo UERJ, ano 15, n. 24, v.1, 2013, p. 312-338.

GASKELL, G. Entrevistas individuais e grupais. In: BAUER, W. M.; GASKELL, G. (ed.). Pesquisa qualitativa com texto, imagem e som. Um manual prático. Trad. Pedrinho A. Guareschi. $2^{\circ}$ ed. Petrópolis: Vozes, 2003, p. 64 -89. 
HERRMANN, M. L. de. P. (org.). Atlas de desastres naturais do estado de Santa Catarina: período de 1980 a 2010. $2^{\circ}$ edição atualizada e revisada. Florianópolis, SC: Instituto Histórico e Geográfico de Santa Catarina, Cadernos Geográfico, 2014, 215p.

MATTEDI, M. A. Subsídios para análise dos desastres. Com Ciência, n. 117, Campinas, 2010.

MURARA, P. Adaptação às inundações urbanas em Rio do Sul, Santa Catarina. Florianópolis: Programa de Pós-graduação em Geografia, Centro de Filosofia e Ciências Humanas, Universidade Federal de Santa Catarina, 2016. 143p. (Tese de Doutorado em Geografia).

NETO, N. T. Pesquisa qualitativa em Geografia. Research Gate, maio de 2013.

PROJETO TSGA. Unidades Demonstrativas de Tecnologias Sociais. Disponível em: < http://tsga.ufsc.br/index.php/2014-12-29-16-35-59/unidades-demonstrativas >. Acesso em: 16 nov. 2017.

RIBEIRO, A. de A. Geograficidade - Risco e desastres em Rio do Sul e Araranguá, Santa Catarina. Florianópolis: Programa de Pós-graduação em Geografia, Centro de Filosofia e Ciências Humanas, Universidade Federal de Santa Catarina, 2020. 332p. (Tese de Doutorado em Geografia).

ROMERO, H.; SMITH, P.; MENDONÇA, M.; MÉNDEZ, M. Macro y mesoclimas del altiplano andino y desierto de Atacama: desafíos y estrategias de adaptación social ante su variabilidad. Revista de Geografia Norte Grande, n. 55, 2013, p. 19-41.

SPÍNDOLA, M. A.; NODARI, E. S. As estiagens no oeste catarinense sob a perspectiva da história ambiental. In: $2^{\circ}$ SIMPÓSIO INTERNACIONAL DE HISTÓRIA AMBIENTAL E MIGRAÇÕES, 17 a 19 set. 2012, Florianópolis. Anais... Florianópolis: LABIMHA, 2012, p. 2691- 2715.

SPINELLI, K. A estiagem e a vulnerabilidade social no oeste de Santa Catarina no período de 1999 a 2012. Florianópolis: Programa de Pós-graduação em Geografia, Centro de Filosofia e Ciências Humanas, Universidade Federal de Santa Catarina, 2018. 309p. (Tese de Doutorado em Geografia).

TWIGG, J. Disaster risk reduction. Mitigation ant preparedness in development ant emergency programming, n. 9. London: Odi, march 2004.

WILCHES-CHAUX, G. La vulnerabilidad global. In: WASKREY, A. (org.). Los Desastres no son naturales. $1993 . \quad$ Disponível <http://www.desenredando.org/public/libros/1993/ldnsn/ >. Acesso em: 25 jul. 2015. 